\title{
Correction to: Some Applications of the Poincaré-Bendixson Theorem
}

\section{Robert Roussarie ${ }^{1}$ (i)}

Accepted: 21 July 2021 / Published online: 25 July 2021

(c) Springer Nature Switzerland AG 2021

\section{Correction to: Qualitative Theory of Dynamical Systems (2021) 20:64 https://doi.org/10.1007/s12346-021-00498-2}

The article Some Applications of the Poincaré-Bendixson Theorem written by Robert Roussarie was originally published online on 10th July 2021 with Open Access under "Creative Commons Attribution (CC BY 4.0)". After publication in volume 20, issue 3, citation ID 64 the author(s) decided to cancel the Open Access. Therefore, the copyright of the article has been changed on 20-07-2021 to () Springer Nature Switzerland AG 2021 with all rights reserved.

Publisher's Note Springer Nature remains neutral with regard to jurisdictional claims in published maps and institutional affiliations.

The original article can be found online at https://doi.org/10.1007/s12346-021-00498-2.

Robert Roussarie

Robert.Roussarie@u-bourgogne.fr

1 Institut de Mathématiques de Bourgogne, Université de Bourgogne-Franche Comté, UMR 5584

CNRS, 2100 Dijon Cedex, France 